\title{
Cardiac Surgery during Pregnancy—our Experience
}

\author{
Vivek Madhav Kanhere ${ }^{1}$, Anjali Vivek Kanhere ${ }^{2 *}$, Devashish Chakravarty ${ }^{3}$, Nikhil Pendse ${ }^{1}$, \\ Milan Pendse ${ }^{3}$, Munir Ahmed Khan ${ }^{3}$, Anita Shrivastava², Vinod Narkhede ${ }^{4}$
}

${ }^{1}$ Department of Surgery, Chirayu Medical College and Hospital, Bhopal, India

${ }^{2}$ Department of Obstetrics and Gynecology, Chirayu Medical College and Hospital, Bhopal, India

${ }^{3}$ Department of Anesthesia, Chirayu Medical College and Hospital, Bhopal, India

${ }^{4}$ Department of Community Medicine, Chirayu Medical College and Hospital, Bhopal, India

Email: *kanhereanju@yahoo.com

How to cite this paper: Kanhere, V.M., Kanhere, A.V., Chakravarty, D., Pendse, N., Pendse, M., Khan, M.A., Shrivastava, A. and Narkhede, V. (2017) Cardiac Surgery during Pregnancy-Our Experience. World Journal of Cardiovascular Surgery, 7, 103-109. https://doi.org/10.4236/wjcs.2017.78012

Received: June 12, 2017

Accepted: August 11, 2017

Published: August 17, 2017

Copyright $\odot 2017$ by authors and Scientific Research Publishing Inc. This work is licensed under the Creative Commons Attribution International License (CC BY 4.0).

http://creativecommons.org/licenses/by/4.0/

\begin{abstract}
Background: Rheumatic heart disease (RHD) continues to be endemic in developing countries like India, thus a number of female patient present with valvular heart disease complicating pregnancy. Surgery is lifesaving in patients who are symptomatic on medical management. Objective: To study maternal and fetal outcome in patient's refractory to medical treatment undergoing cardiac surgery during pregnancy. Methodology: Analysis of 8 pregnant patients who underwent cardiac surgery during 5 years from Jan 2012 to Dec 2016 in a Medical college setup in Central India. Results: Maternal age ranged between 20 - 35 mean of 23.75, NYHA class IV, refractory to medical treatment. The underlying cardiac lesion was rheumatic heart disease 7 (87.5\%) cases, $6(85.7 \%)$ had mitral valve lesion. 7 primigravida (87.5\%) patients were taken as elective procedure in second trimester (18 - 26 weeks), one multipara patient as emergency after failed Balloon mitral valvuloplasty (BMV) in third trimester of pregnancy (32 weeks) was the only maternal death. $5(62.5 \%)$ patients progressed to term pregnancy and delivered vaginally. The cardiopulmonary bypass variables studied were Median bypass time 51.25 minutes (range 37 - 78), median cross-clamp time 25.62 minutes (range 16 - 48), Median flow rate $2.4 \mathrm{l} / \mathrm{min} / \mathrm{m}^{2}$ (range 2.2 - 2.6) mean perfusion pressure during CPB 65 - 89 (range $55-120$ ) and median perfusate temperature $37^{\circ} \mathrm{C}$ (range 32 - 38). 2 (29\%) patients had a long term follow-up and have delivered at term in their next pregnancies at the institute. Conclusion: Cardiac Surgery can be performed during pregnancy in patients' refractory to medical management. The outcome is better with mother than fetus. Multidisciplinary team approach is the strategy for care.
\end{abstract}




\section{Keywords}

Cardiac Surgery, Cardiopulmonary Bypass, Fetal Outcome, Maternal

Outcome, Pregnancy

\section{Introduction}

Rheumatic heart disease (RHD) continues to be endemic in developing countries like India, majority of these patients are female. In developing countries, RHD occurs in younger age group thus a small number of them present with valvular heart disease complicating pregnancy. Non obstetric mortality in pregnancy is high with heart disease. It occurs in $1 \%-3 \%$ of pregnancies and accounting for $10 \%-15 \%$ of maternal mortality [1]. Common Obstetric ICU admission in nonobstetric cases includes cardiac disease during pregnancy [2].

When a woman is pregnant may develop cardiac failure due to increased cardiorespiratory requirements. This can happen in a diagnosed cardiac case or can be the first presentation of the disease. Surgery is lifesaving in patients who are symptomatic on medical management. It provides a favorable prognosis with maternal outcome though has high fetal risks. Thus, surgical treatment of heart diseases during pregnancy and puerperium is performed only in selected cases. [2].

We present our experience with cardiac surgery performed during pregnancy in these patients who were refractory to medical treatment.

\section{Methodology}

Retrospective observational study was done on 8 pregnant patients who underwent cardiac surgery during 5 years from Jan 2012 to Dec 2016 in a Medical college setup in Central India.

Inclusion Criteria: consenting antenatal patients requiring cardiac surgery refractory to medical treatment, and booked for pregnancy follow-up and delivery in the same institute.

The following maternal variables were studied: a) preoperative variables, including age, New York Health Association class, heart disease, parity, gestational age at the time of operation $b$ ) intraoperative variables, including type of procedure, CPB duration (in minutes), Cross clamp time and temperature; and c) postoperative variables, cardiac complications including hemorrhage, infections, morbidity and death.

We also analyzed the occurrence of fetal losses, which included spontaneous abortion, IUFD/intrauterine fetal death (up to 20 weeks of gestation), stillbirth or neonatal death (up to 28 days after birth), and prematurity (birth up to 37 weeks of gestation).

Descriptive statistical analysis of maternal and newborn results was performed using the mean and standard deviation. Permission of institutional ethical com- 
mittee was taken.

All patients had routine lab investigation, chest X-ray (with abdominal shield), electrocardiography (ECG), echocardiography and Obstetric ultrasound.

To ensure optimal maternofetal outcome a care provider team of cardiac surgeon, anesthesiologist, intensivist, obstetrician and pediatrician was formed.

Surgical and anesthetic techniques followed the recommendations established for cardiac surgery.

All patients had 5 lead ECG, pulse oximetry, end tidal Co2, invasive arterial pressure and central venous pressure monitoring. Perioperative transesophageal echocardiography was performed by Sonosite multiplane $5 \mathrm{MHz}$ probe.

Anesthesia was induced by intravenous thiopentone, midazolam, and muscle relaxation achieved by vecuronium. Maintenance of anaesthesia was by $80 \%$ oxygen $20 \%$ air mixture and sevoflurane as inhalation agent.

Cardiopulmonary Bypass (CPB) was carried out using ascending aortic and bicaval cannulation. Blood cardioplegia was used and scavenged through a small right atriotomy so as to minimize the serum potassium levels during $\mathrm{CPB}$. $\mathrm{Pa}$ tients were kept normothermic, on high flow.

Patient was placed supine with slight left lateral tilt. Median sternotomy was made.

All valves were replaced using 2.0 Ethibond horizontal mattress sutures and St Jude mechanical bileaflet valves were used in all patients.

As maximum patients were operated in second trimester Cardiotocography was not done, on return to intensive care Unit (lCU) fetal heart monitoring was done by fetal Doppler and ultrasonography.

\section{Results}

Maternal age ranged between 20 - 35 mean of 23.75. The underlying cardiac lesion was predominantly rheumatic heart disease corresponding to $7(87.5 \%)$ cases [Table 1], among this mitral valve lesion was in 6 (85.7\%) cases [Table 2]. All the patients were in NYHA class IV and refractory to medical treatment.

$7(87.5 \%)$ patients were taken as elective procedure in second trimester (18 26 weeks) were primigravida, one patient was taken as emergency after failed BMV in third trimester of pregnancy (32 weeks) was multipara [Table 3].

Table 1. Spectrum of disease.

\begin{tabular}{cccc}
\hline Type of disease & Number $\mathrm{n}=8$ & percentage & NYHA classification \\
\hline Congenital & 01 & $12.5 \%$ & IV \\
Rheumatic & 07 & $87.5 \%$ & IV \\
\hline
\end{tabular}

Table 2. Rheumatic disease presentation.

\begin{tabular}{ccc}
\hline Valve involved & Number $\mathrm{n}=7$ & percentage \\
\hline Mitral valve disease & 06 & $85.7 \%$ \\
Aortic valve disease & 01 & $14.2 \%$ \\
\hline
\end{tabular}


Table 3. Maternal details.

\begin{tabular}{|c|c|c|c|c|c|c|c|c|}
\hline Case & 1 & 2 & 3 & 4 & 5 & 6 & 7 & 8 \\
\hline Age & 22 & 35 & 20 & 20 & 20 & 22 & 25 & 26 \\
\hline Parity & G1P0 & G1P0 & G1P0 & G1P0 & G1P0 & G1P0 & G1P0 & G3P1L1 \\
\hline $\begin{array}{c}\text { Gestational age at } \\
\text { surgery }\end{array}$ & 18 & 26 & 26 & 22 & 18 & 21 & 19 & 32 \\
\hline Type of surgery & MVR * & $\begin{array}{c}\text { ASD } \\
\text { CLOSURE** }^{*}\end{array}$ & MVR & MVR & MVR & MVR & $\operatorname{AVR}^{* * *}$ & MVR \\
\hline ICU stay (hours) & 48 & 36 & 48 & 36 & 36 & 38 & 36 & 7 days \\
\hline $\begin{array}{l}\text { Hospital stay } \\
\text { (days) }\end{array}$ & 12 & 10 & 12 & 10 & 10 & 10 & 11 & 9 \\
\hline Fetal outcome & $\begin{array}{c}\text { Survived } \\
\text { Neodeath }\end{array}$ & Survived & Survived & $\begin{array}{l}\text { Survived } \\
\text { Neodeath }\end{array}$ & Survived & IUFD $^{* * * *}$ & IUFD & IUFD \\
\hline Maternal outcome & Survived & Survived & Survived & Survived & Survived & Survived & Survived & Death \\
\hline
\end{tabular}

MVR-Mitral valve replacement ${ }^{*}$ AVR-Atrial valve replacement ${ }^{* * *}$ ASD-Atrial septal defect closure ${ }^{* *}$ IUFD-Intrauterine fetal demise at 21 weeks, 19 weeks, 32 weeks, case $6,7,8$ respectively ${ }^{* * * *}$ Neodeath-death of a live born infant during first 28 days of birth.

$5(62.5 \%)$ patients progressed to term pregnancy, all delivered vaginally .No maternal complication was observed only two neonatal death was reported. 3 (37.5\%) patients had IUFD (intrauterine fetal death) [Table 3]. These were seen on the first postoperative day to the fifth postoperative day period. All these responded to medical method of induction, delivered vaginally without complication.

Only one patient died who was operated as an emergency case with severe acute mitral regurgitation after failed BMV in third trimester of pregnancy (32 weeks) because of infection, sepsis and multiorgan failure on $5^{\text {th }}$ postoperative day.

The cardiopulmonary bypass variables studied were Median bypass time 51.25 minutes (range 37 - 78), median cross-clamp time 25.62 minutes (range 16 - 48), Median flow rate $2.4 \mathrm{l} / \mathrm{min} / \mathrm{m}^{2}$ (range 2.2 - 2.6) mean perfusion pressure during $\mathrm{CPB} 65$ - 89 (range 55 - 120) and median perfusate temperature $37^{\circ} \mathrm{C}$ (range 32 38) [Table 4].

$2(29 \%)$ patients had a long term follow-up and have delivered at term in their next pregnancies at the institute.

\section{Discussion}

Counselling and management of women of childbearing age with suspected cardiac disease should start before pregnancy occurs. Cardiac surgery during pregnancy has many factors to consider and needs a multidisciplinary approach in treating the patient for better maternal and fetal outcome. Proper selection of patients in second trimester refractory to medical treatment is an important factor. In our study the predominance was of mitral valve disease (85.7\%) requiring surgery during pregnancy is similar to the observation done by S. Chandrasekhar et al. [3] and Ávila et al. [4].

All our patients were NYHA class IV with progressive hemodynamic and res- 
Table 4. Cardiopulmonary bypass details.

\begin{tabular}{ccc}
\hline CP details & range & average \\
\hline Median bypass time & $37-78$ minutes & 51.25 minutes \\
Median cross-clamp & $16-48$ minutes & 25.62 minutes \\
Median flow rate & $2.2-2.61 / \mathrm{min} / \mathrm{m}^{2}$ & $2.41 / \mathrm{min} / \mathrm{m}^{2}$ \\
Mean perfusion pressure during CPB & $55-120$ & $65-89$ \\
Median perfusion temperature & $32^{\circ} \mathrm{C}-38^{\circ} \mathrm{C}$ & $37^{\circ} \mathrm{C}$ \\
\hline
\end{tabular}

piratory deterioration, despite medical treatment, same observation was seen in a study by Arnoni et al. [5].

The mean gestational age of patients in our study who had surgery was 22 weeks. As per the study by Ávila et al. [4] the mean gestational age was 20 weeks. The study by Arnoni et al. [5] mentions the mean gestational age as 22 weeks. The earlier need to undergo surgery refractory to medical management in second trimester shows the likelihood of progression to hemodynamic deterioration throughout pregnancy and during delivery and puerperium is potentially very high. The best period for surgery is between the 13th and 28th week, as per the recommendation by ESC Guidelines on the management of cardiovascular diseases during pregnancy [5].

Median bypass time observed in our study was 51.25 minutes (range 37 - 78), median cross-clamp time 25.62 minutes (range 16 - 48), Median flow rate 2.4 $1 / \mathrm{min} / \mathrm{m}^{2}$ (range 2.2 - 2.6) mean perfusion pressure during СРB 65 - 89 (range 55 - 120) and median perfusate temperature $37^{\circ} \mathrm{C}$ (range 32 - 38). Maternal hematocrit $>28 \%$ is recommended to optimize the oxygen delivery. In our study the hematocrit was 30.36. This was consistent with the report from Mayo Clinic by Gurley et al. [6] and also as per the recommendation by ESC Guidelines on the management of cardiovascular diseases during pregnancy [7].

Cardiac surgery carried out on cardiopulmonary bypass (CPB) in a pregnant woman is associated with poor neonatal outcomes although maternal outcomes are similar to cardiac surgery in non-pregnant women [8]. Optimal management of pregnant patients undergoing $\mathrm{CPB}$ are maintaining high pump flow rates, normothermic $\mathrm{CPB}$, pulsatile perfusion and keeping the $\mathrm{CPB}$ time as short as possible [9] [10].

One maternal mortality in our study was in third trimester of pregnancy. The maternal death rate in our study group was $12.5 \% .7 .5 \%$ maternal death rate was found in Ávila et al. [4] study, 8.6\% was reported by Arnoni et al. [5], and of 13.3\% described by Salazar et al. [11] This death was related to poor tolerance of sudden acute severe MR post BMV with emergency nature of the surgery and advanced pregnancy in third trimester.

As regards the fetal outcome, fetal loss was seen in $25 \%$ as fetal demise in postoperative period. $62.5 \%$ progressed till term. The fetal mortality rate during maternal cardiac surgery with CPB ranges from $16 \%$ to $33 \%$ as cited by A. Patel 
et al. [12] Pieper et al. [13]. There were two early neonatal deaths in our group.

As regards the pregnancy outcome all patients had vaginal delivery. Intrauterine fetal deaths were induced with prostaglandin derivatives. There was no complication observed with the delivery.

As regards the maternal outcome as discussed only one maternal death occurred. Two patients had successful repeat pregnancies and deliveries with the same team.

Effective team work, counseling and documentation are first line of treatment of patients undergoing cardiac surgery during pregnancy [14].

\section{Conclusion}

Cardiac Surgery can be performed during pregnancy in patients' refractory to medical management. It is well tolerated by the mother though the fetal mortality rate is high. The developments in surgical and interventional technologies, critical care techniques, monitoring and therapies, are resulting in improvements in outcomes for pregnant patients requiring cardiac intervention. This is likely to occur making the maternal and fetal outcomes better. Multidisciplinary team approach is the strategy for patient care.

\section{Limitation}

This is a study with small number of patients as the condition itself has limitations.

\section{Acknowledgements}

Author would like to acknowledge the contributions of his perfusion team Mr. Abhay Bapat and Mrs. Nidhi Gupta in managing the patients. He would like to thank his staff surgical and managerial for the same. He would like to thank the patients for being a part of the study group.

\section{Institutional Ethical Approval}

Obtained.

\section{References}

[1] Royal College of Obstetricians and Gynaecologists (2004) Why Mothers Die 20002002-The Sixth Report of Confidential Enquiries into Maternal Deaths in the United Kingdom. RCOG Press, London.

[2] Martin, S.R. and Foley, M.R. (2006) Intensive Care in Obstetrics: An Evidence Based Review. American Journal of Obstetrics \& Gynecology, 195, 673-689. https://doi.org/10.1016/j.ajog.2006.05.042

[3] Ávila, W.S., Gouveia, A.M.M., Pomerantzeff, P., Bortolotto, M.R.L., Grinberg, M., Stolf,' N. and Zugaib, M. (2009) Maternal-Fetal Outcome and Prognosis of Cardiac Surgery during Pregnancy. Arquivos Brasileiros De Cardiologia, 93, No. 1.

[4] Chandrasekhar, S., Cook, C.R. and Collard, C.D. (2009) Cardiac Surgery in the Parturient. Anesthesia \& Analgesia, 108, 777-786. 
https://doi.org/10.1213/ane.0b013e31819367aa

[5] Arnoni, R.T., Arnoni, A.S., Bonini, R.C.A., de Almeida, A.F., Neto, C.A., Dinkhuysen, J.J., et al. (2003) Risk Factors Associated with Cardiac Surgery during Pregnancy. The Annals of Thoracic Surgery, 76, 1605. https://doi.org/10.1016/S0003-4975(03)01188-3

[6] Gurley, Fionnuala, M., et al. (2006) Cardiac Surgery during Pregnancy: The Mayo Clinic Experience 1976-2005. Circulation, 114, 356.

[7] European Society of Gynecology (ESG), Association for European Pediatrics Cardiology (AEPC), German Society for Gender Medicine (DGesGM), et al. (2011) Esc Guidelines on the Management of Cardiovascular Diseases during Pregnancy: The Task Force on the Management of Cardiovascular Diseases during Pregnancy of the European Society of Cardiology (Esc). European Heart Journal, 32, 3147-3197. https://doi.org/10.1093/eurheartj/ehr218

[8] Kapoor, M.C. (2014) Cardiopulmonary Bypass in Pregnancy. Annals of Cardiac Anaesthesia, 17, 33-39. https://doi.org/10.4103/0971-9784.124133

[9] Mishra, M., Sawhney, R., Kumar, A., Bapna, K.R., Kohli, V., Wasir, H. and Trehan, N. (2014) Cardiac Surgery during Pregnancy: Continuous Fetal Monitoring Using Umbilical Artery Doppler Flow Velocity Indices. Annals of Cardiac Anaesthesia, 17, 46-51. https://doi.org/10.4103/0971-9784.124141

[10] Yuan, S.M.2014) Indications for Cardiopulmonary Bypass during Pregnancy and Impact on Fetal Outcomes Indication for Cardiopulmonary Bypass during Pregnancy and Impact on Fetal Outcomes. Geburtshilfe Frauenheilkd, 74, 55-62. https://doi.org/10.1055/s-0033-1350997

[11] Salazar, E., Espinola, E., Molina, F.J., Reyes, A. and Barragán, R. (2001) Heart Surgery with Cardiopulmonary Bypass in Pregnant Woman. Arquivos Cardiology Mexico, 71, 20.

[12] Patel, S., Asopa, A., Tang, T.M. and Ohri, S.K. (2008) Cardiac Surgery during Pregnancy. Texas Heart Institute Journal, 35, 307-312.

[13] Pieper, P.G., Hoendermis, E.S. and Drijver, Y.N. (2012) Cardiac Surgery and Percutaneous Intervention in Pregnant Women with Heart Disease. Netherlands Heart Journal, 20, Article ID: 125128.

[14] Kanhere, A.V. and Kanhere, V.M. (2016) Pregnancy after Cardiac Surgery. The Journal of Obstetrics and Gynecology of India, 66, 10-15.

https://doi.org/10.1007/s13224-016-0841-y 
Submit or recommend next manuscript to SCIRP and we will provide best service for you:

Accepting pre-submission inquiries through Email, Facebook, LinkedIn, Twitter, etc. A wide selection of journals (inclusive of 9 subjects, more than 200 journals)

Providing 24-hour high-quality service

User-friendly online submission system

Fair and swift peer-review system

Efficient typesetting and proofreading procedure

Display of the result of downloads and visits, as well as the number of cited articles Maximum dissemination of your research work

Submit your manuscript at: http://papersubmission.scirp.org/

Or contact wjcs@scirp.org 